\title{
INTEGRATING MONITORING TECHNIQUES FOR A BURIED SINKHOLE IN AN URBAN ENVIRONMENT
}

\section{Gabriella B Williams}

University of Sheffield, Western Bank, Sheffield, S102TN, United Kingdom, gbwilliams1@sheffield.ac.uk

\section{Dr. Vanessa J Banks}

British Geological Survey, Environmental Science Centre, Nicker Hill, Keyworth, Nottingham, NG12 5GG, United

Kingdom,vbanks@bgs.ac.uk

\section{Dr. Elisabeth T Bowman}

University of Sheffield, Western Bank, Sheffield, S102TN, e.bowman@sheffield.ac.uk

\section{Dr. Anthony H Cooper}

British Geological Survey, Environmental Science Centre, Nicker Hill, Keyworth, Nottingham, NG12 5GG, United Kingdom,ahc@bgs.ac.uk

\section{Lee $D$ Jones}

British Geological Survey, Environmental Science Centre, Nicker Hill, Keyworth, Nottingham, NG12 5GG, United Kingdom,ldjon@bgs.ac.uk

\section{Matthew P Kirkham}

British Geological Survey, Environmental Science Centre, Nicker Hill, Keyworth, Nottingham, NG12 5GG, United

Kingdom,mki@bgs.ac.uk

\section{David J R Morgan}

British Geological Survey, Environmental Science Centre, Nicker Hill, Keyworth, Nottingham, NG12 5GG, United Kingdom,djrm@bgs.ac.uk

\section{Dr. Paul Shepley}

University of Sheffield, Western Bank, Sheffield, S10 2TN, p.shepley@sheffield.ac.uk

\begin{abstract}
Ripon is a historic city and market town in North Yorkshire. It is unique in being the only city in the UK to define planning zones based on the potential for bedrock dissolution. The underlying geology comprises marls, limestone and gypsum of the Permian Edlington, Brotherton and Roxby formations, capped by glacial deposits (till). It is the rapid rate of dissolution of the gypsum (hydrated calcium sulphate) that enables the karst to evolve on human time scales. Following the collapse that formed a sinkhole in the rear garden of a property in Magdalens Road, Ripon, UK in November 2016 the British Geological Survey, funded by a Natural Environment Research Council grant, initiated a programme of monitoring of a nearby depression. This feature is forming in a recreation area and is one that local residents reported to have grown in dimensions.
\end{abstract}

The density of development precludes the use of satellite-based monitoring systems. Instead, we have inte- grated ground-based LiDAR imaging with geophysical techniques (micro-gravity and passive seismic). Monitoring has revealed that this depression lies over a palaeosinkhole that is in the order of $10 \mathrm{~m}$ in diameter and extends to a depth of a similar order of magnitude. The monitoring has been continued in the context of $\mathrm{PhD}$ research (University of Sheffield) that is more broadly focused on understanding sinkhole triggering processes. The developing sinkhole is on the eastern side of Ripon close to the southerly flowing River Ure, where upwelling confined groundwater contributes to the river base flow. In this context the hypotheses that growth can be correlated with rainfall or river discharge can be tested.

\section{Introduction}

On the night of 9th November 2016 a sinkhole opened in the rear garden of a terraced house in Ripon, North Yorkshire, UK. This required the evacuation of seven houses at the eastern end of the terrace. The British Geological 
Survey (BGS) responded with a team that worked alongside the emergency services and monitored the impact using an unmanned aerial vehicle (UAV) to obtain aerial images (Figure 1). Ripon is a historic city and market town in North Yorkshire with a legacy of sinkhole impacts. It is unique in being the only city in the UK to define planning zones based on the potential for bedrock dissolution (Cooper, 1998). The underlying bedrock geology comprises marls, limestone and gypsum of the Permian Roxby, Brotherton and Edlington formations (Figure 2). The bedrock is capped by glacial deposits including Till and Glaciofluvial sand and gravel deposits. It is the rapid rate of dissolution of the gypsum (hydrated calcium sulphate) that enables the karst to dissolve on human time scales.

The sinkhole was remediated with a concrete plug. BGS was successful in obtaining Natural Environment Research Council Urgency funding (NE/P020933/1) to investigate the remediated feature using geophysical techniques (micro-gravity, electrical resistivity tomography and passive seismic) that are sensitive to changes in the density of the ground. These techniques successfully constrained the geometry of the feature. The technique of nesting the sensors by re-occupying predefined monitoring points was used to determine sub-surface change. However, the footprint of sinkhole remediation overlapped with that of an earlier sinkhole making it difficult to interpret the results.

During the monitoring of the sinkhole behind the terrace of houses, local residents reported that they had noticed that a hollow in a park (Paddies Park; Figure 3) immediately to the east of the terrace had grown during recent months. The park is open to the public and is managed by Harrogate Borough Council. With the permission of the Council, this feature has become the focus for the monitoring being undertaken as part of a $\mathrm{PhD}$ investigating triggering processes in gypsum karst.

\section{Research Question}

In the UK, gypsum is not widespread. Triassic gypsum is thin and lies bedded between impermeable mudstone where it is protected from water. However, Permian gypsum is thicker and sinkholes have been recorded on a belt approximately $3 \mathrm{~km}$ wide and $100 \mathrm{~km}$ long in the north east of England (Farrant \& Cooper, 2008). They are most common close to rivers, where buried valleys reduce the thickness of the mudstone cover (Cooper, et

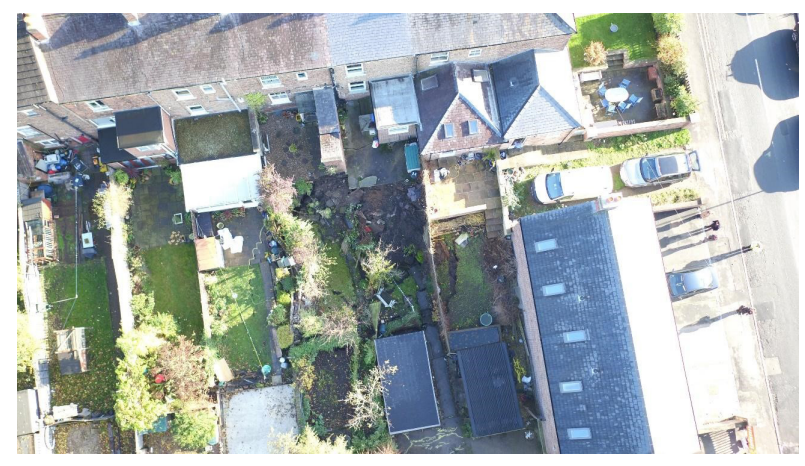

Figure 1. UAV survey of the sinkhole feature in November 2016. (Reproduced from British Geological Survey data (C) UKRI (2019) with permission).

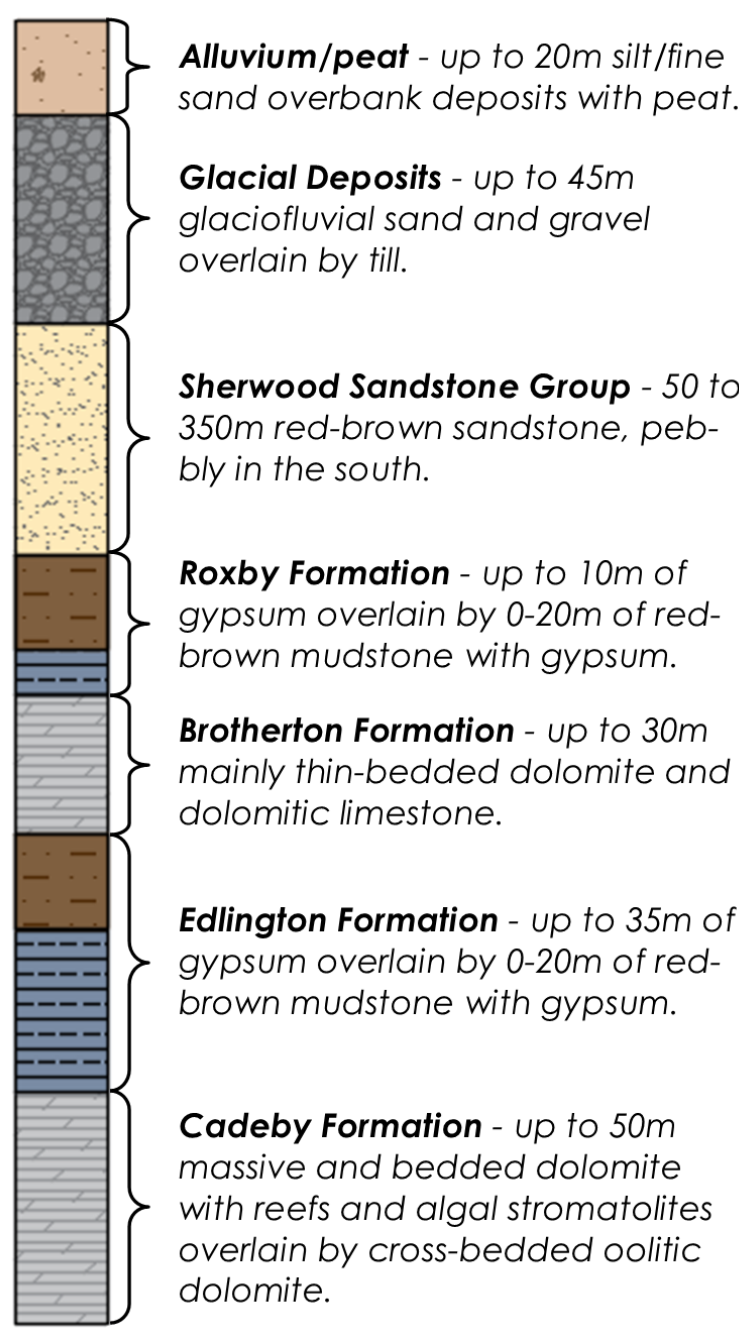

Figure 2. Geological sequence encountered in the Ripon area, see Figure 4 for legend. 


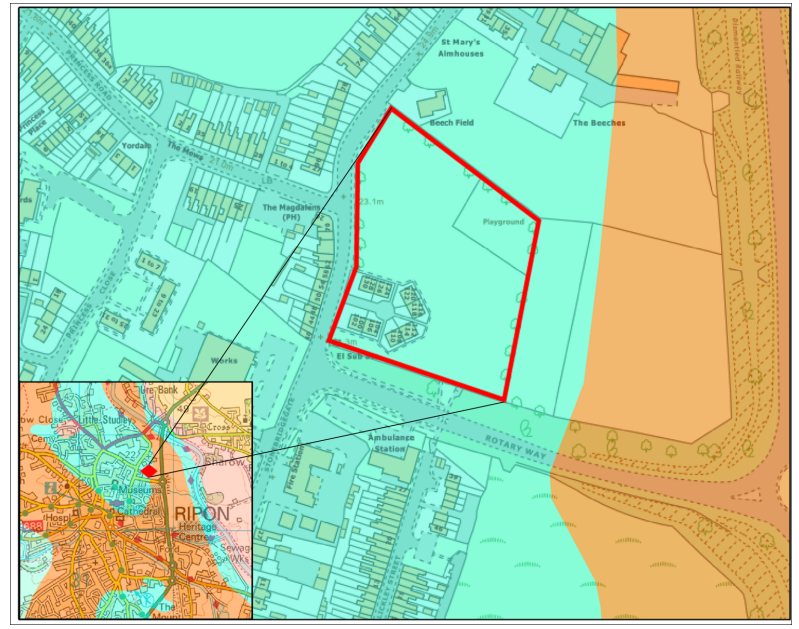

Figure 3. Bedrock geology of the Paddies Park area (red) showing the Brotherton Formation (blue) and Edlington Formation (orange) (Reproduced from British Geological Survey data (C) UKRI (2019) with permission. Contains Ordnance Data (C) Crown Copyright and database rights 2020. Ordnance Survey Licence no. 100021290).

al., 2013). Ripon lies upon this belt and at the confluence of the River Ure with the River Skell, which is suspected to be the cause of the high sinkhole rate.

Due to the eastward dip of the Permian rocks and the higher ground to the west of the gypsum belt, water in the Cadeby Eormation aquifer (Figure 2) experiences artesian pressures. The water is confined by the impermeable mudstone of the Edlington Formation. In Ripon and surrounding areas, artesian springs contain dissolved carbonates and sulphates. This indicates that the water has passed through and dissolved gypsum from the Edlington Formation before upwelling where the mudstone is thinned by a buried valley (Figure 4; Cooper, et al., 2013). This information provides the basis for understanding how collapse sinkholes form in Ripon. However, buildings in Ripon have also been affected by slow subsidence. A previous survey of a proposed building site found a $40 \mathrm{~m}$ column of soft silty deposits, filling an old sinkhole (Patterson, et al., 1995).

When a sinkhole collapses it creates a column of broken rock and sediments which extends upwards from the gypsum layer at depth, and therefore connects the confined artesian aquifer and unconfined perched aquifer. When buried, it is not known whether this connection always persists and what effect this has on the hydrology of the area, it depends on the nature of the fill. At depth, there may be interaction between developing collapse sinkholes and previously buried sinkholes formed higher in the sequence.

The buried sinkhole that is being monitored is in the order of $10 \mathrm{~m}$ in diameter, and is approximately $50 \mathrm{~m}$ from the location of the 2016 collapse sinkhole. It is on the eastern side of Ripon close to the southerly flowing River Ure. The park is situated on the dolomitic limestone of the Brotherton Formation, but an outcrop of the older Edlington Formation, consisting of mudstone and gypsum, lies directly to the east of the park, where the buried valley is suspected (Figure 3). Boreholes show at least $15 \mathrm{~m}$ of superficial deposits in the area.

The purpose of this study is to monitor the rate at which the depression grows and to determine the subsurface conditions including stratigraphy and mechanical properties. This will feed into a larger study aiming to produce a conceptual model of Ripon hydrogeology and sinkhole triggering mechanisms. It will involve further geophysical investigation of the location of the buried valley, a hydrological investigation to find the chemical composition of upwelling confined groundwater and the rate at which it contributes to the river base flow.

\section{Methods}

The monitoring of the buried sinkhole in Paddies Park is being undertaken using ground based LiDAR, together with nested microgravity and passive seismic techniques (Figure 5). The gravity technique relies on measuring small variations in the earth's gravitational force due to density contrasts in the ground that might be attributable to sub-surface dissolution or collapse. It is undertaken using a LaCoste \& Romberg Graviton EG Meter. The Graviton is an all-in-one, fully automated, self-levelling portable gravity meter based on highly sensitive zerolength spring sensor technology with a typical repeatability of $3 \mu \mathrm{Gal}$ under field conditions.

During the survey, control readings are taken at the base station approximately every two hours. A line of microgravity survey stations has been established across the site using station spacings of $10 \mathrm{~m}$ around the depression and $5 \mathrm{~m}$ directly over the depression. Raw microgravity data are automatically corrected by the gravity meter software for Earth tides, ambient temperature and tilt. 


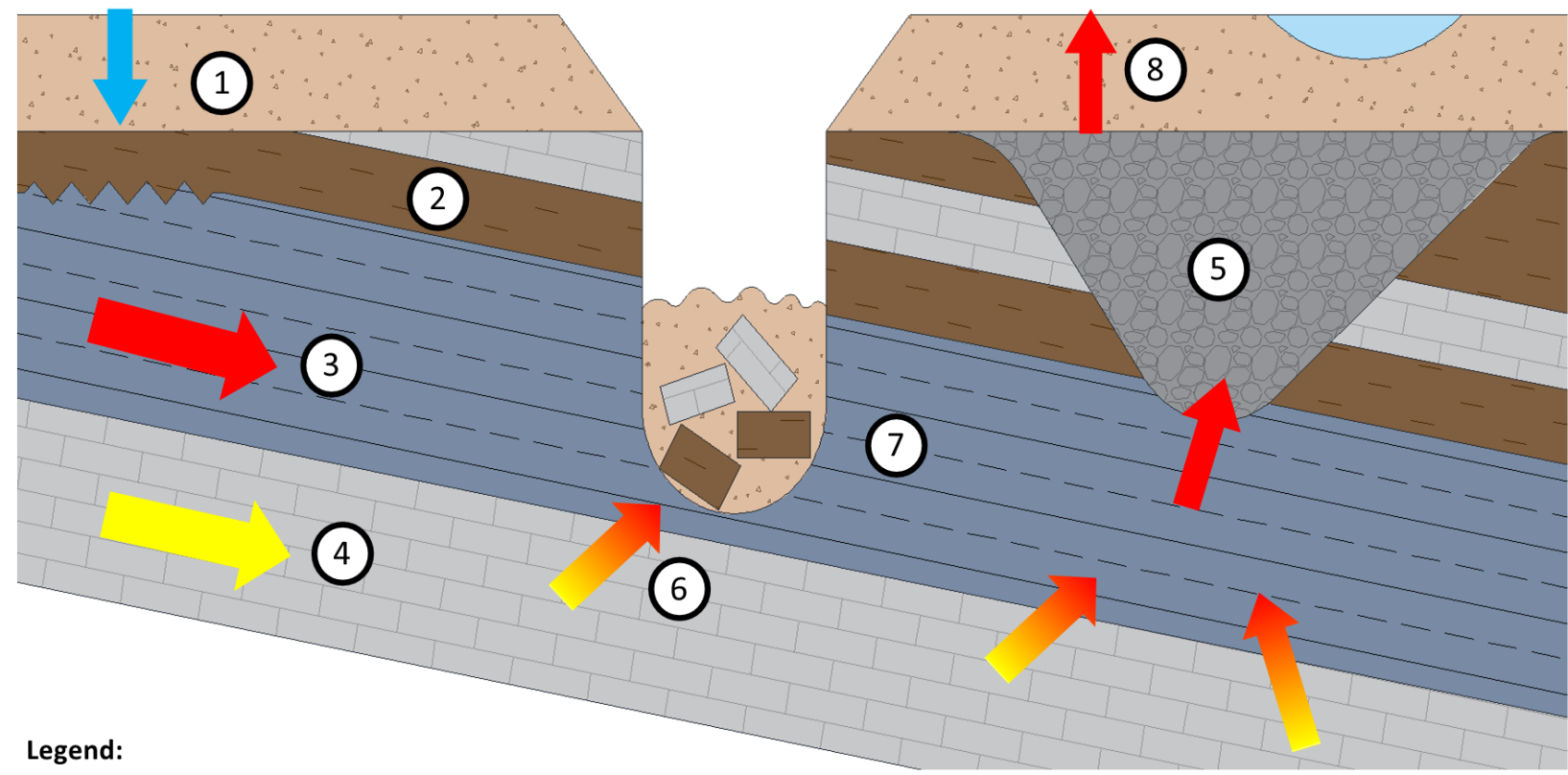

Mudstone

Limestone and dolomite

Interbedded gypsum and marl

Surface deposits-alluvium and till

River terrace deposits-

gravel and sand
Recharge occurs to the west into dolomite. Some

(1) recharge water also enters and dissolves gypsum where it is close to the surface, creating a feather edge.

(2) Mudstone acts as an a quitard.

Calcium sulphate saturated water (red arrow) travels eastwards through gypsum layer.

(4) Calcium magnesium carbonate saturated water (yellow arrow) travels through the dolomite layer.
(5)

6

6) saturated with respect to calcium sulphate, and is still aggressive towards gypsum.

Voids form in areas of high flow, eventually forming collapse sinkholes. These later get filled with soft sediments

(8) The now saturated water emerges as a sulphate spring.

Figure 4. Conceptual model for sinkhole formation, modified from Cooper et al. (2013).

Readings are manually corrected for short-term instrumental drift using the base station readings and assuming linear drift between base readings. The raw data are corrected to a common datum (gravity data reduction), such as the geoid, in order to remove the effect of features that are not of direct geological interest. The gravity anomaly is derived from the difference between observed gravity values and those determined either from a theoretical prediction for the same location, or relative to the gravity benchmark station (Micro-g LaCoste, 2007).

The seismic technique uses seismic noise, which exists everywhere, consisting mainly of low-amplitude sur- face waves produced by the constructive interference of $\mathrm{P}$ and $\mathrm{S}$ waves in near-surface layers. Generally frequencies $<1 \mathrm{~Hz}$ are associated with natural phenomena (wind action, waves, variations in atmospheric pressure), whilst frequencies $>1 \mathrm{~Hz}$ are associated with man-made sources (road traffic, trains, machinery etc.) and are termed microtremors. Microtremor measurements from a single station allow the seismic resonance induced by the presence of strong impedance (velocity $\mathrm{x}$ density) contrasts in the subsurface to be recorded. Such impedance contrasts can then be detected by calculation of the horizontal to vertical spectral ratio (HVSR) of noise records. Peak $\mathrm{H} / \mathrm{V}$ values represent maximum imped- 


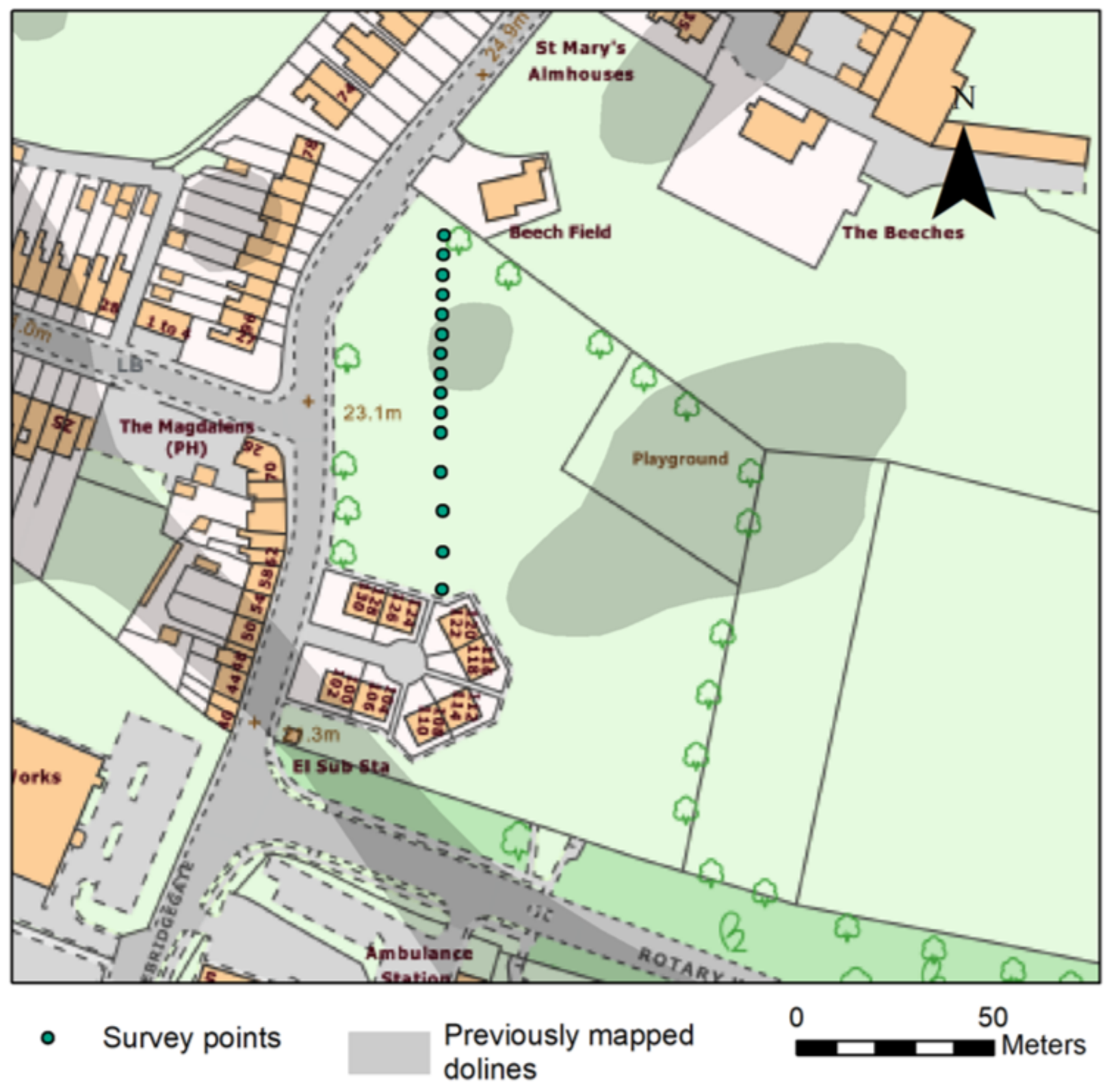

Figure 5. Survey point positions. Note that the previously mapped dolines are outdated and their position is not accurate. Contains Ordnance Data (C) Crown Copyright and database rights 2020. Ordnance Survey Licence no. 100021290.

ance contrast, often associated with a soil layer overlying bedrock. An estimate of the shear wave velocity vs is required for processing and interpretation. For the SH-resonance frequency in a single layer of thickness $h$ above the bedrock resonator $f_{0}=\frac{v_{s}}{4 h}$. The local survey grid, as established for the microgravity survey, is occupied by the seismometer. Monitoring is carried out using a Tromino digital 3-component seismometer (Micromed s.p.a., 2009). At each station a shallow hole is excavated $(\sim 5-10 \mathrm{~cm}$ deep), clearing away any soft loose soil and the surface approximately levelled. The Tromino unit is then set firmly into the ground stabilized by three spikes, whilst ensuring the base plate is in good mechanical contact with the ground and aligned N-S. Seismic noise is recorded for 12 minutes. The microtremor data are processed using the 'Grilla' software package (Micromed s.p.a., 2009), applying the SESAME Project methodology and criteria (Bard, 2004). Calculation of 
the $\mathrm{H} / \mathrm{V}$ curves uses geological information from nearby borehole records and from the BGS Borehole database. An average shear wave velocity vs of $300 \mathrm{~m} / \mathrm{s}$ has been assumed for the cover sequence. The curves are used to calculate the impedance using the software, which produces a vertical cross section of impedance plotted using colour-filled contours.

Repeat topographical surveys are carried out to establish the exact baseline elevation of the buried sinkhole. The survey is carried out with a Leica System 1200 Total Station used to obtain highly accurate elevations with a Leica VIVA Real-Time Kinematic Differential GPS system using a Leica VIVA GS15 GNSS smart antenna for general purpose surveying. The positional measurement accuracy quoted by the manufacturer for this system in Network-RTK mode is $<1 \mathrm{~cm}$ in the horizontal direction and $<2 \mathrm{~cm}$ in the vertical direction. The LiDAR scanning and processing workflow that is employed follows standard methodological procedures (Jones, 2017). The scans are geo-rectified using the corresponding GNSS data, aligned using multi-station adjustment algorithms, and attributed with RGB and Amplitude (Intensity) values. This work is carried out in RiScanPro and the data are exported as ASCII (txt) or LAS files. The data are then imported into one of six software packages in order to grid, map or model the data and one of two software packages in order to visualise it.

\section{Results}

A region of low impedance (June 2019), coincident with the surface depression measures $20 \mathrm{~m}$ across and extends $30 \mathrm{~m}$ below the ground surface (Figure 6).

The LiDAR scan of Paddies Park shows the depth of the depression to be approximately $50 \mathrm{~cm}$ (Figure 7). The scan also shows that the eastern side of the park is slightly lower, and highlights further depressions in the park.

The microgravity anomaly plots from a preliminary survey in December 2017 and the first of a series of quarterly surveys in June 2019 show a well-developed doline (Figures 8 and 9).

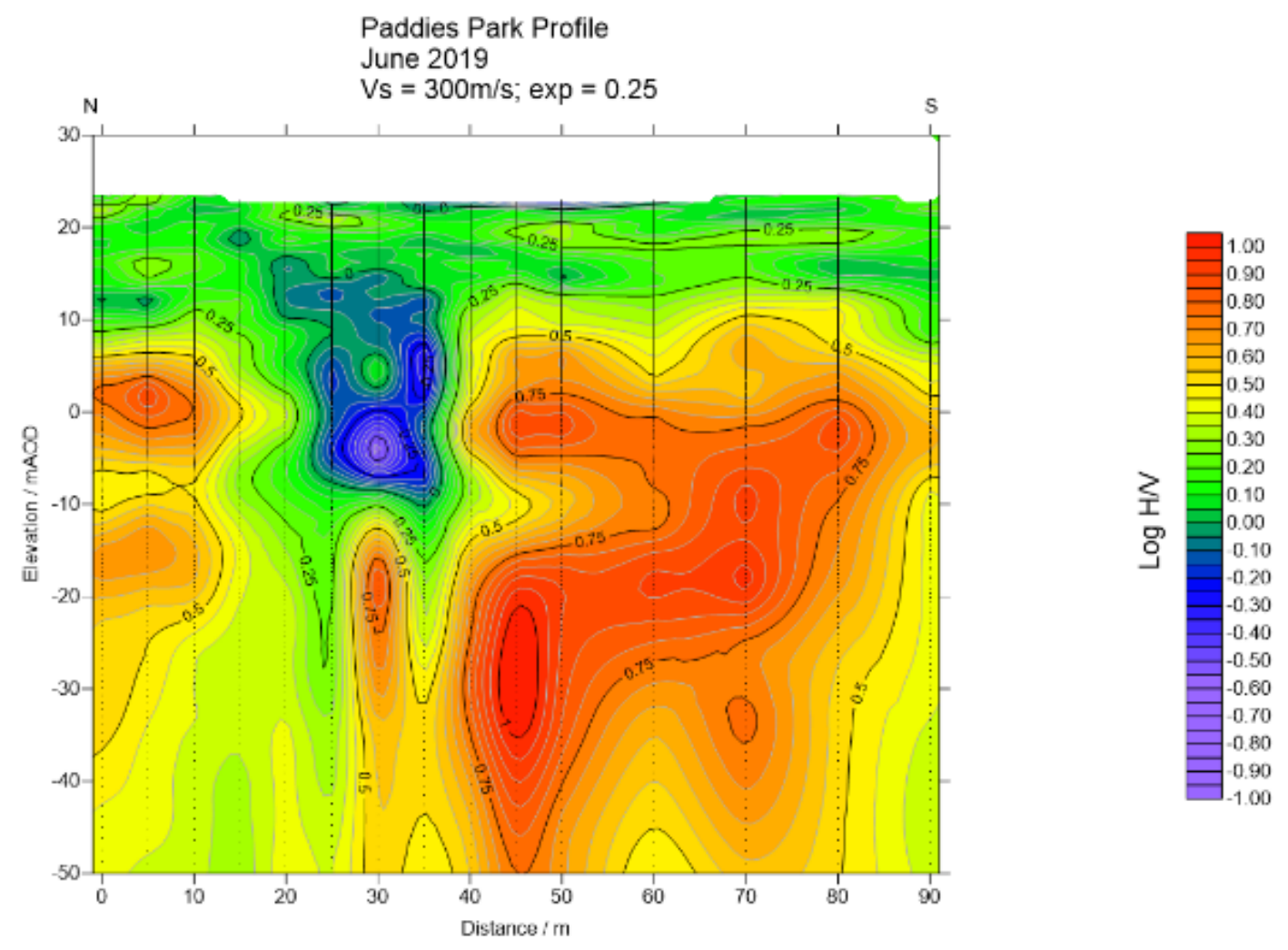

Figure 6. Contour plot of impedance from H/V ratio across Paddies Park depression. 


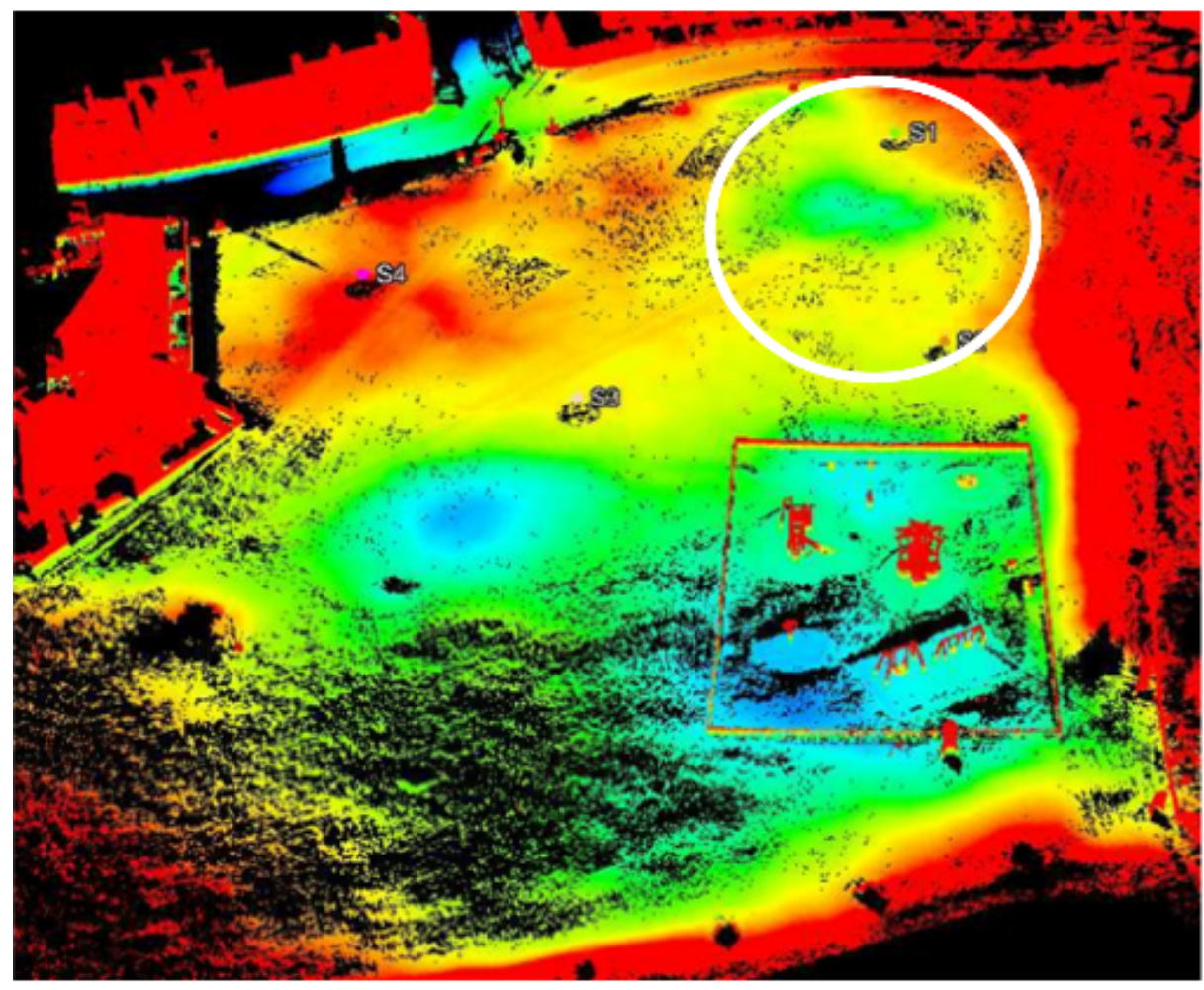

Elevation (m)

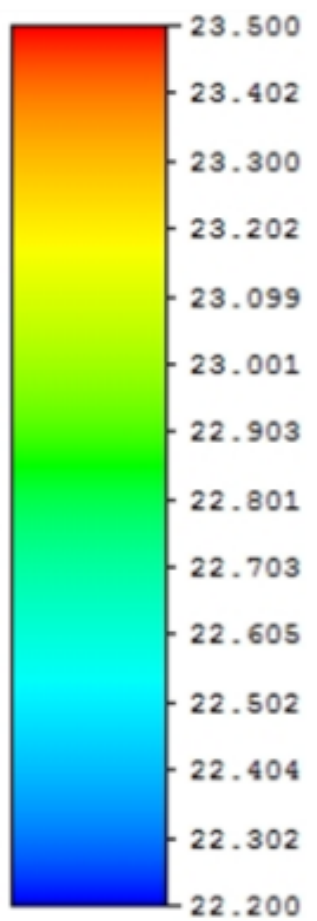

Figure 7. Aerial view of LiDAR scan (NNE to the right). Surveyed sinkhole in top right corner as indicated in white. Elevation in meters above mean sea level.

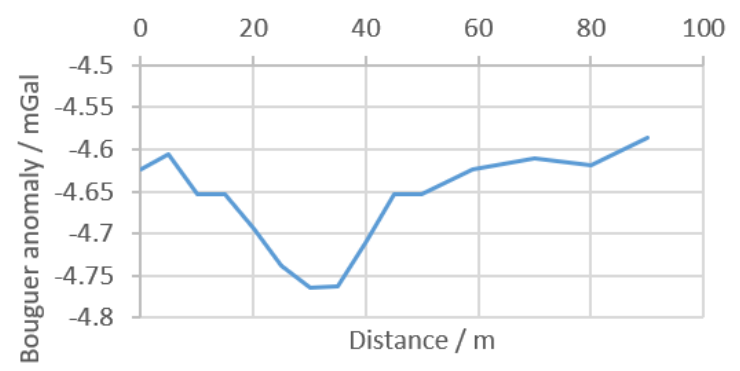

Figure 8. Paddies Park gravity profile December 2017. Line of section shown in Figure 5.

\section{Discussion}

Both the gravity surveys and passive seismic surveys show a clear change in the ground composition where the depression lies. The negative gravity anomaly indicates a region of lower density, while the passive seismic results indicate an area of low impedance in the same region.

The LiDAR scan highlights the depression and allows its depth to be estimated. Further LiDAR scans will be used to detect subsequent changes in depth at millime-

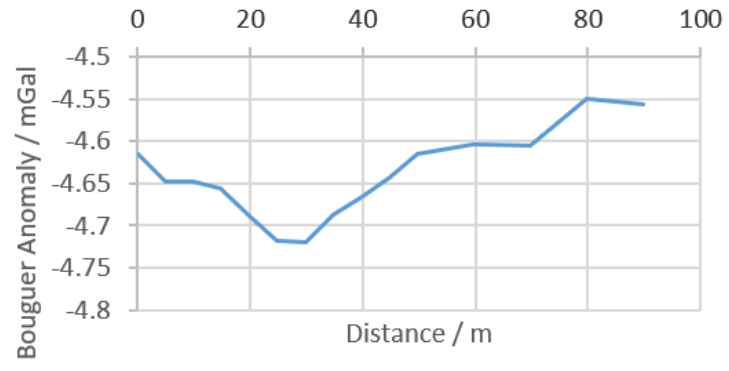

Figure 9. Paddies Park gravity profile - June 2019. Line of section shown in Figure 5.

ter scale. The scan also identifies further depressions to the west of the park that were previously mapped. While these appear deeper than the depression being surveyed, they are situated within a larger area that has subsided.

The passive seismic result shows an impedance contrast at approximately $15 \mathrm{~m}$ depth, where the rockhead is anticipated. This result was achieved using a shear wave velocity input of $300 \mathrm{~m} / \mathrm{s}$, typical of gravel. However, geology maps indicate the area is overlain by glacial 
clay, and initial in situ shear wave velocity tests using a SoilSpy Rosina seismograph returned values of approximately $100 \mathrm{~m} / \mathrm{s}$. In this case it may be that the impedance contrast is associated with a change of soil type at a shallower depth. Further investigation and material testing is required to determine an appropriate value for Vs and the increase exponent. A feature is also present at approximately $30 \mathrm{~m}$ below ground level. The slightly lower impedance across the entire section possibly indicates another change in strata.

The micro-gravity profile shows the anomaly has decreased between December 2017 and June 2019 (i.e., the ground density has increased). There are a number of reasons for this change, including seasonal moisture content changes, further compaction of the ground or inaccuracy in the measuring equipment. Further quarterly surveys will be conducted in the future to monitor the continuous change with time.

\section{Conclusions}

Using LiDAR and geophysical survey equipment, a subsiding buried sinkhole has been successfully identified. The depression footprint has been more accurately measured with a LiDAR scan, which shows it to be $20 \mathrm{~m}$ wide and $30 \mathrm{~m}$ long. It has an approximate north-south elongation that probably relates to it being joint controlled as seen elsewhere in Ripon (Cooper, 1986).

Passive seismic surveys and microgravity surveys were taken across the short axis of the depression. The passive seismic surveys show a column of high impedance material approximately $20 \mathrm{~m}$ wide and $30 \mathrm{~m}$ deep directly below the depression. This indicates a region of lower density or higher porosity. The microgravity surveys show a negative anomaly approximately $30 \mathrm{~m}$ across. This is again indicative of a region of lower density material beneath the depression. From these geophysical surveys it can be concluded that the depression lies over a former collapse sinkhole which has been filled with loose soil deposits and possibly low density peat deposits. The cause of the depression is the compaction of these deposits.

There is some evidence to suggest this compaction will continue - between the two microgravity surveys the negative anomaly decreased, suggesting an increase in density. Quarterly surveys planned in the next year will be used to monitor seasonal and absolute changes in the size and composition of the buried sinkhole.
In order to interpret the results further, investigation into the properties of the soil, such as the density, shear wave velocity and water content are required. Once these have been determined it will be possible to draw further conclusions about the composition of the site and sinkhole fill, and the mechanics of its subsidence. In the future, integration of the subsidence data with hydrological data such as rainfall and river flow data will provide insight into groundwater flow patterns and how these trigger collapse or buried sinkholes.

\section{References}

Bard PY. 2004. Guidelines for the implementation of the $\mathrm{H} / \mathrm{V}$ spectral ratio technique on ambient vibrations: measurements, processing and interpretation, SESAME European research project, WP12Deliverable D23. 12. EVG1-CT-2000-00026.

Cooper AH. 1986. Foundered strata and subsidence resulting from the dissolution of Permian gypsum in the Ripon and Bedale areas, North Yorkshire. 127-139 in Harwood GM, Smith DB. (eds.). The English Zechstein and related topics. Geological Society of London, Special Publication, 22.

Cooper AH. 1998. Subsidence hazards caused by the dissolution of Permian gypsum in England: geology, investigation and remediation. 265-275 in: Geohazards in engineering geology, Maund JG, Eddleston M (eds.). Geological Society of London. Special Publications in Engineering Geology, 15.

Cooper AH, Odling NE, Murphy PJ, Miller C, Greenwood CJ, Brown DS. 2013. The Role of Sulfate-Rich Springs and Groundwater in the Formation of Sinkholes over Gypsum in Eastern England. In: Land L, Doctor DH, Stephenson JB (eds.) Sinkholes and the Engineering and Environmental Impacts of Karst: Proceedings of the Thirteenth Multidisciplinary Conference May 6 through 10, 2013, Carlsbad, New Mexico. Carlsbad, New Mexico, National Cave and Karst Research Institute (NCKRI), 141-150, 10pp. (NCKRI Symposium 2).

Farrant AR, Cooper AH. 2008. Karst geohazards in the UK: the use of digital data for hazard management. Quarterly Journal of Engineering Geology and Hydrogeology, Volume 41, pp. 339-356.

Jones LD. 2017. Ground-Based Geomatic Surveys at the BGS - A Manual for Specialist Data Collection 
and Processing. British Geological Survey Open Report, OR/17/40, 43pp.

Micro-g LaCoste, 2007. Graviton-EG User’s Manual (Revision 1.8.) 51pp.

Micromed s.p.a. 2009. The Short Tromino how to, Ver. 1.1.26pp.

Patterson D, Davey JC, Cooper AH, Ferris JK. 1995. The application of microgravity geophysics in a phased investigation of dissolution subsidence at Ripon, Yorkshire. Quarterly Journal of Engineering Geology, Vol. 28, 83-94. 